\title{
Clinical characteristics and outcomes of children with COVID-19 in Saudi Arabia
}

Abeer A. Alnajjar, MD, Ahmed M. Dohain, MD, Gaser A. Abdelmohsen, MD, Turki S. Alahmadi, MD, Zaher F. Zaher, MD, Abobakr A. Abdelgalil, MD.

\begin{abstract}
الأهداف : تحديد الخصائص السكانية و الأعراض السريرية وكذلك الأمراض

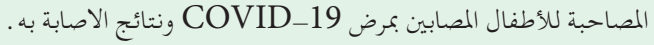

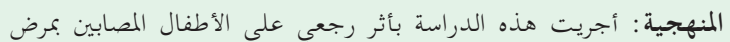

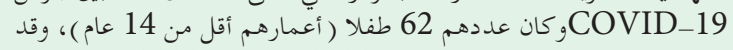

أجريت الدراسة في الفترة بين 2 مارس جامعة الملك عبد التزيز بجدة الفترة بين المملكة العربية السعودية .

النتائج: تضمنت الدراسة 62 مريضا أعمارهم أقل من 14 سنه، 9 أطفاء أمرال

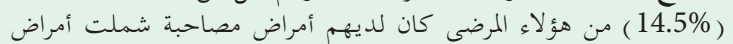

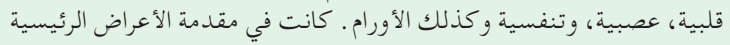

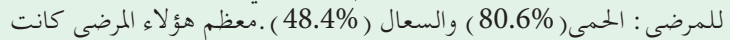

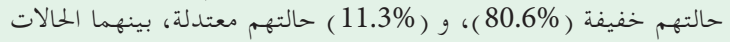

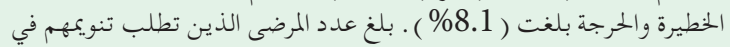

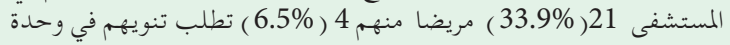

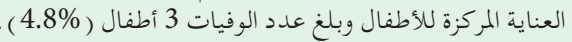

الحخلاصة : وجدنا أن الأطفال في الأعمار المختلفة عرضة لمرض كور كورونا المستجاد

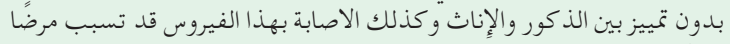
حرجًا في الأطفال لدرجة الذوفاة.
\end{abstract}

Objectives: To determine the demographic and clinical characteristics, underlying comorbidities, and outcomes of children with coronavirus disease 2019 (COVID-19) infection.

Methods: In this retrospective study, we reported 62 pediatric patients (age $<14$ years) with confirmed COVID-19 between March 2 and July 1, 2020, at King Abdulaziz University Hospital, Jeddah, Saudi Arabia.

Results: Comorbid conditions, including cardiac, neurological, respiratory, and malignant disorders, were reported in 9 patients $(14.5 \%)$. The most prominent presenting complaints were fever $(80.6 \%)$ and cough $(48.4 \%)$. Most of our patients $(80.6 \%)$ had mild disease, $11.3 \%$ had moderate disease, and $8.1 \%$ exhibited severe and critical illness. Twenty-one patients (33.9\%) were hospitalized, with 4 patients $(6.5 \%)$ admitted to the pediatric intensive care unit, and $3(4.8 \%)$ patients died.

Conclusion: All pediatric age groups are susceptible to COVID-19, with no gender difference. COVID-19 infection may result in critical illness and even mortality in subsets of pediatric patients.

Keywords: COVID-19, SARS-CoV-2, clinical characteristics, children, comorbidities

Saudi Med J 2021; Vol. 42 (4): 391-398 doi: 10.15537/smj.2021.42.4.20210011

From the Department of Pediatrics (Alnajjar, Dohain, Abdelmohsen, Alahmadi, Zaher, Abdelgalil), King Abdulaziz University, Jeddah, Kingdom of Saudi Arabia; and from the Department of Pediatrics (Dohain, Abdelmohsen, Abdelgalil), Cairo University, Cairo, Egypt.

Received 6th January 2021. Accepted 6th March 2021.

Address correspondence and reprint request to: Dr. Abobakr A. Abdelgalil, Department of Paediatrics, King Abdulaziz University, Jeddah, Kingdom of Saudi Arabia. E-mail: bakrsree@gmail.com ORCID ID: https://orcid.org/0000-0002-1639-0723

Since December 2019, the world has been facing $\checkmark$ an unprecedented health care challenge, namely, coronavirus disease 2019 (COVID-19), which was initially identified in Wuhan (China), and has since quickly spread all over the world. ${ }^{1}$ On March 2, 2020, the Kingdom of Saudi Arabia reported the first case of severe acute respiratory syndrome coronavirus-2 (SARS$\mathrm{CoV}-2){ }^{2}$ As of November 18,2020 , according to the Saudi Ministry of Health, 354,208 confirmed cases of COVID-19 have been reported in Saudi Arabia, with 5,710 (1.6\%) deaths. ${ }^{3}$

Early reports of SARS-CoV-2 infection noted the rarity of the disease in children. ${ }^{4,5}$ Data from China and 
the United States demonstrated that only approximately $2 \%$ of all confirmed COVID-19 cases were under the age of 15 years. ${ }^{6,7}$ In Italy, children represented $1.2 \%$ of all COVID-19 patients. $^{8,9}$

So far, the majority of COVID-19 cases have occurred in adults, and as a result, the disease has been less well described in children. ${ }^{10}$ The available data demonstrated that children are less likely to have severe symptoms of COVID-19 when compared to adults, with around $95 \%$ of all cases being asymptomatic or having mild to moderate manifestations of the disease. Moreover, only $2 \%$ of pediatric patients were admitted to the pediatric intensive care unit (PICU) or needed mechanical ventilation. ${ }^{9}$

Several risk factors for the severity of the illness have been determined in adult patients with COVID-19, while this is yet to be identified in children, ${ }^{11,12}$ as previous reports showed that more than $80 \%$ of critically ill children with COVID-19 have had significant underlying medical conditions. ${ }^{13}$

As the pandemic spreads, reports of its occurrence in children are increasing, and the understanding of the disease is improving. Although previous studies have described the epidemiological and clinical features of COVID-19 in children, there is a knowledge gap in this field in different parts of the world.

One of the earliest studies from the Middle East describing the clinical features of COVID-19 in children in this region. ${ }^{14}$ In this study, we aimed to present the demographic and clinical characteristics, comorbidities, severity, and outcomes of SARS-CoV-2 in children in Saudi Arabia.

Methods. We conducted a retrospective review of all pediatric patients $(<14$ years) who tested positive for SARS-CoV-2 between March 2 and July 1, 2020, at King Abdulaziz University Hospital, Jeddah, Saudi Arabia. Real-time reverse transcription-polymerase chain reaction (PCR) was used to confirm the diagnosis by testing a nasopharyngeal swab specimen based on the protocol established by the World Health Organization. ${ }^{2}$ COVID-19 positive patients with missing data were excluded.

All pediatric patients who were tested either had clinical suspicion of COVID-19 or a history of contact with SARS-CoV-2 positive cases. The decision to admit a child to the pediatric ward or PICU was at the

Disclosure. Authors have no conflict of interests, and the work was not supported or funded by any drug company. discretion of the attending physicians. The study was approved by our Institutional Review Board (Reference No. 702-20) and conducted in accordance with the tenets of the Declaration of Helsinki.

Demographic information, clinical symptoms, signs, epidemiological history, underlying medical conditions, laboratory results, radiological findings, management plans, and outcomes were obtained from hospital medical records. Laboratory and imaging investigations were performed based on the evaluation of an attending pediatrician and the clinical condition of the patient. According to the classification described by Dong et $\mathrm{al},{ }^{15}$ the patients were categorized as asymptomatic, mild, moderate, severe, and critical cases.

Statistical analysis. Data were collected retrospectively, and statistical analysis was performed using SPSS for Windows, version 26 (IBM Corp, Armonk, NY, USA). Nominal variables were presented as number (percentage). Numeric variables were presented as medians and ranges (minimummaximum). Comparisons between nominal variables were tested using $\chi^{2}$ and Fisher exact tests, and $p<0.05$ was considered statistically significant.

Results. We included 62 pediatric patients who presented to the emergency department, and COVID-19 infection was confirmed. The children represented around 4.2\% (62 out of 1490) of confirmed COVID-19 cases in our institution during the study period. The median age was 6 years (the youngest was 2.5 months and the oldest was 13 years). Most patients had a Saudi Arabian nationality (59.7\%). There was no specific gender predominance as the numbers of males and females were equal. Most patients had a history of contact with COVID-19 patients (77.4\%), particularly family members $(66.1 \%)$, while $22.6 \%$ of patients had unknown exposure. Notably, $6.5 \%$ of the cases were children of healthcare providers (Table 1).

Clinical features. Fever was reported in $80.6 \%$ of patients but was documented in the hospital only in $27.4 \%$ of cases. The median duration of documented fever for hospitalized patients was 2 days (range, 1-9 days). The most common respiratory manifestations were cough $(48.4 \%)$, rhinorrhea $(27.4 \%)$, sore throat $(17.7 \%)$, and shortness of breath (12.9\%) (Table $1 \&$ Figure 1). All patients with shortness of breath (8 cases, $12.9 \%$ ) were hospitalized, and 4 of them were admitted to the PICU with respiratory failure that required mechanical ventilation.

Regarding gastrointestinal manifestations, diarrhea occurred in 15 patients (24.2\%), vomiting in 11 patients $(17.7 \%)$, and abdominal pain in 6 patients $(9.7 \%)$. A 
Table 1 - Demographic variables, exposures, and clinical characteristics of children with COVID-19 (N=62).

\begin{tabular}{|c|c|}
\hline Demographics & n (\%) \\
\hline Age, years & $6(0.2-13)$ \\
\hline \multicolumn{2}{|l|}{ Gender } \\
\hline Male & $31(50)$ \\
\hline Female & $31(50)$ \\
\hline \multicolumn{2}{|l|}{ Nationality } \\
\hline Saudi & $37(59.7)$ \\
\hline Yemeni & $9(14.5)$ \\
\hline Indian & $5(8.1)$ \\
\hline Others & $11(17.7)$ \\
\hline \multicolumn{2}{|l|}{ Exposures } \\
\hline History of contact with COVID-19 positive patient & $48(77.4)$ \\
\hline COVID-19 positive family member & $41(66.1)$ \\
\hline COVID-19 positive patient outside family & $7(11.3)$ \\
\hline Unknown exposure & $14(22.6)$ \\
\hline Parents are health care providers & $4(6.5)$ \\
\hline \multicolumn{2}{|l|}{ Clinical manifestations } \\
\hline History of fever & $50(80.6)$ \\
\hline Documented fever in hospital & $17(27.4)$ \\
\hline \multicolumn{2}{|l|}{ Fever category $\left({ }^{\circ} \mathrm{C}\right)$} \\
\hline $37.7-38$ & $8(12.90)$ \\
\hline$>38-39$ & $8(12.90)$ \\
\hline$>39$ & $1(1.61)$ \\
\hline Fever duration, days & $2(1-9)$ \\
\hline \multicolumn{2}{|l|}{ Respiratory symptoms } \\
\hline Cough & $30(48.4)$ \\
\hline Runny nose & $17(27.4)$ \\
\hline Sore throat & $11(17.7)$ \\
\hline Shortness of breath & $8(12.9)$ \\
\hline Anosmia & $1(1.6)$ \\
\hline \multicolumn{2}{|l|}{ General non-specific symptoms } \\
\hline Headache & $6(9.7)$ \\
\hline Body aches & $3(4.8)$ \\
\hline Myalgia & $5(8.1)$ \\
\hline \multicolumn{2}{|l|}{ Gastrointestinal symptoms } \\
\hline Diarrhea & $15(24.2)$ \\
\hline Vomiting & $11(17.7)$ \\
\hline Abdominal pain & $6(9.7)$ \\
\hline Skin rash & $1(1.6)$ \\
\hline Seizures & $3(4.8)$ \\
\hline Associated comorbidities & $9(14.5)$ \\
\hline Congenital heart disease & $3(4.8)$ \\
\hline Bronchial asthma/adenoid/bronchiolitis obliterans & $3(4.8)$ \\
\hline Malignancy (rhabdomyosarcoma) & $1(1.6)$ \\
\hline Hydrocephalous (brain atrophy) & $2(3.2)$ \\
\hline
\end{tabular}

maculopapular rash was reported in one patient. Three patients developed seizures; in 2 of them, this was preceded by a fever. These 2 patients had underlying hydrocephalus, brain atrophy, and seizure disorder.

Comorbidities, including congenital heart disease (3 cases), brain atrophy secondary to hydrocephalus

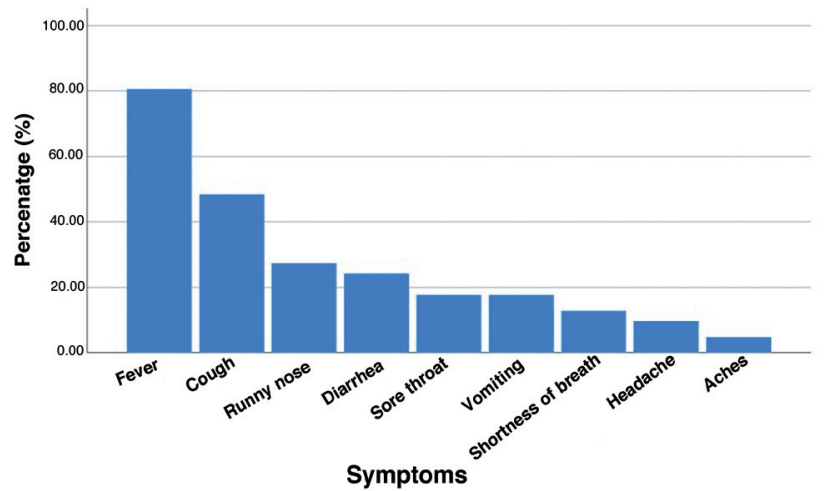

Figure 1 - The frequency of symptoms reported in children with COVID-19.

(2 cases), rhabdomyosarcoma (one case), bronchial asthma (one case), bronchiolitis obliterans (one case), and adenoid hypertrophy causing significant upper airway obstruction (one case), were reported in 9 patients $(14.5 \%)$. The clinical characteristics of the patients are summarized in Table $1 \&$ Figure 1.

Among 22 patients who had a complete blood count, one patient had leukopenia (white blood cells $<4 \mathrm{~K} / \mu \mathrm{L}), 5(22.7 \%)$ (lymphocytic count $<1.5 \mathrm{~K} / \mu \mathrm{L}$ ) had lymphopenia, and $4(18.2 \%)$ (neutrophil count $<1.5 \mathrm{~K} / \mu \mathrm{L}$ ) had neutropenia. None of the patients had anemia, and 2 had thrombocytopenia (platelets $<150$ $\mathrm{K} / \mu \mathrm{L}$ ). C-reactive protein level was recorded in 20 and elevated in $8(40 \%)$ patients, while D-dimer level was recorded in 9 patients and elevated in 7 (77.8\%). Lactate dehydrogenase level showed significant elevation in 6 out of $7(85.7 \%)$ patients, while ferritin levels were elevated in one out of 7 patients (14.3\%). Among the 21 patients who had undergone a kidney function test, only one patient had an abnormally elevated serum creatinine level. Cardiac enzymes were elevated in 2 patients, both categorized as critical illness.

Among the 20 patients that underwent chest radiography in this cohort, 9 had a normal study, 7 showed bilateral consolidative opacities, 3 showed peripheral ground-glass opacities, and one showed mild pleural effusion. Table 2 summarizes the laboratory results and chest radiography findings of the studied patients. Echocardiography was performed for 3 out of 4 critical patients, showing cardiac dysfunction in one and mild pericardial effusion in the other 2 patients. In addition, it was performed in one patient with severe illness and revealed impaired left ventricular function.

Four patients presented with low oxygen saturation ( $<94 \%$, measured by pulse oximetry) and required oxygen supplementation. Most patients were managed 
Table 2 - Laboratory results and imaging studies in COVID-19 among children.

\begin{tabular}{|c|c|c|c|c|}
\hline Parameter & $\begin{array}{c}\text { Number of } \\
\text { patients }\end{array}$ & $\begin{array}{c}\text { Patients with } \\
\text { abnormal results }\end{array}$ & Measured values & $\begin{array}{c}\text { Reference } \\
\text { range }\end{array}$ \\
\hline \multicolumn{5}{|l|}{ Laboratory data } \\
\hline Complete blood count & 22 & & & \\
\hline Hemoglobin, gm/dl & & 4 & $11.7(6.50-14)$ & $10.2-16$ \\
\hline WBCs, $\mathrm{K} / \mu \mathrm{L}$ & & 4 & $7.65(2.3-26)$ & $4.5-17.5$ \\
\hline Platelets, $\mathrm{K} / \mu \mathrm{L}$ & & 4 & $300(104-520)$ & $150-450$ \\
\hline Neutrophils, K/ $\mu \mathrm{L}$ & & 6 & $3.3(0.5-21)$ & $1-8.5$ \\
\hline Lymphocytes, $\mathrm{K} / \mu \mathrm{L}$ & & 16 & $2.6(0.7-12.4)$ & $4-10.5$ \\
\hline $\mathrm{CRP}, \mathrm{mg} / \mathrm{L}$ & 20 & 8 & $3(3-268)$ & $0-3$ \\
\hline Liver enzymes & 20 & & & \\
\hline AST, U/L & & 11 & $39(13-79)$ & $15-37$ \\
\hline ALT, U/L & & 0 & $30(7-59)$ & $12-78$ \\
\hline Renal functions & 21 & & & \\
\hline Urea, $\mathrm{mmol} / L$ & & 3 & $3.8(1.4-22)$ & $2.5-6.4$ \\
\hline Creatinine, $\mu \mathrm{mol} / L$ & & 1 & $32.5(13-440)$ & $53-115$ \\
\hline Ferritin, $\mathrm{ng} / \mathrm{ml}$ & 7 & 1 & $246(9-2264)$ & $30-400$ \\
\hline D-dimer & 9 & 7 & $1.1(0.2-40)$ & $0-0.5$ \\
\hline $\mathrm{LDH}, \mathrm{U} / \mathrm{L}$ & 7 & 6 & $344(200-1284)$ & $100-240$ \\
\hline Cardiac enzymes & 2 & & & \\
\hline Troponin-I, $\mu \mathrm{g} / \mathrm{L}$ & & 2 & $1.29(0.59-2)$ & $0.02-0.04$ \\
\hline Creatine kinase, IU/L & & 2 & $393(388-398)$ & $26-308$ \\
\hline Bacterial blood culture & 14 & 0 & Negative & \\
\hline \multicolumn{5}{|l|}{ Radiological findings } \\
\hline Chest X-ray, $n(\%)$ & & $20(100)$ & & \\
\hline Normal & & $9(45)$ & & \\
\hline Peripheral ground-glass opacities & & $3(15)$ & & \\
\hline Bilateral consolidative opacities & & $7(35)$ & & \\
\hline Pleural effusion & & $1(5)$ & & \\
\hline
\end{tabular}

either at home $(66.1 \%)$ or in the isolation section of the general pediatric ward (27.4\%). Most of the patients $(91.9 \%)$ had mild to moderate disease, and only 4 patients $(6.5 \%)$ had a critical illness that necessitated PICU admission and mechanical ventilation. Only one, with bronchiolitis obliterans, developed a severe illness and required non-invasive ventilation in the pediatric ward. Eventually, she improved and was discharged home. Three $(4.8 \%)$ out of the 4 critical patients died; among them, 2 had developed multi-organ dysfunction, and one developed acute respiratory distress syndrome (ARDS).

Hospitalization was more frequent in infants $(<1$ year) than in other age groups $(p<0.021$, Figure 2$)$. Most of the patients did not require any medications $(45.1 \%)$ or received only symptomatic treatment (33.9\%). Other administered treatment included antibiotics (10 cases), intravenous immunoglobulin (3 cases), hydroxychloroquine (2 cases), tocilizumab ( 2 cases), and steroids (one case). Table 3 summarizes

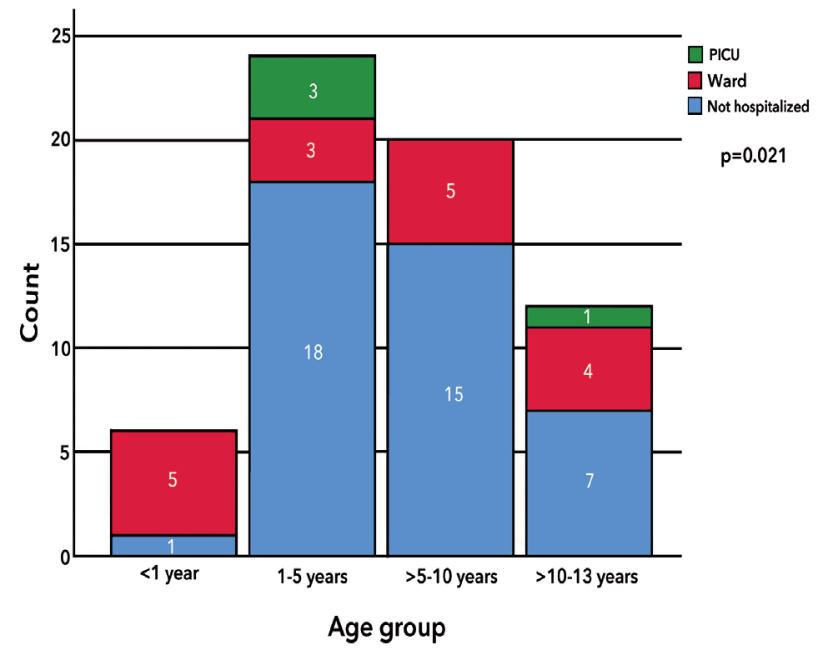

Figure 2 - The level of management of COVID-19 in different pediatric age groups. PICU: pediatric intensive care unit 
Table 3 - Clinical outcomes and therapies administered to children with COVID-19.

\begin{tabular}{lcc}
\hline Parameter & $\mathbf{n}(\%)$ & Outcome \\
\hline Severity & $50(80.6)$ & Improved \\
Mild & $7(11.3)$ & Improved \\
Moderate & $1(1.6)$ & Improved \\
Severe & $4(6.5)$ & 3 Deaths, 1 improved \\
Critical & & \\
Admission & $4(6.5)$ & 3 Deaths, 1 improved \\
PICU admission & $17(27.4)$ & Improved \\
Ward admission & $41(66.1)$ & Improved \\
Not hospitalized & $5(2-18)$ & \\
Duration of hospital admission, days & & \\
Oxygen requirement & $56(90.3)$ & Improved \\
No oxygen needed & $1(1.6)$ & Improved \\
Nasal cannula & $1(1.6)$ & Improved \\
Non-invasive ventilation & $4(6.5)$ & 3 Deaths, 1 improved \\
Mechanical ventilation & & \\
Treatment & $28(45.1)$ & Improved \\
No treatment & $21(33.9)$ & Improved \\
Symptomatic & $10(16.1)$ & 1 died \\
Antibiotics & $1(1.6)$ & Death \\
Hydroxychloroquine, IVIG, tocilizumab & $1(1.6)$ & Improved \\
Hydroxychloroquine, IVIG, steroid & $1(1.6)$ & Death \\
Tocilizumab and IVIG & Values are presented as numbers and percentage $(\%)$. PICU: pediatric intensive care unit, \\
\hline IVIG: Intravenous immunoglobulin & \\
\hline & & \\
\hline
\end{tabular}

the clinical outcomes and therapeutic modalities used in this cohort.

Discussion. Knowledge of the clinical characteristics of COVID-19 in children needs to be continuously updated to help in mapping out the disease, identifying risk factors, and guiding the management. Very few reports have described COVID-19 among children outside of China, Europe, and the United States. This study adds to the previous knowledge on children with COVID-19 by shedding light on the clinical features and outcomes of a sample of pediatric patients diagnosed with the disease in Saudi Arabia.

In our study, the predominant nationality among the patients was Saudi Arabia (59.7\%). There were 4 children with parents working at a health care facility $(6.5 \%)$, which is similar to the results of a study describing the characteristics of the population infected with SARS-CoV-2 in Saudi Arabia. ${ }^{2}$

Multiple studies have reported higher SARS-CoV-2 infection in males than in females. 5,16,17 However, there were no gender differences in this study and other previous reports. ${ }^{18}$ In this analysis, $66.1 \%$ of the patients had contact with a family member infected with COVID-19. Previous studies showed that most of the infected children had a familial history of positive contact (Table 4). ${ }^{9,19,20}$

A systematic review including 62 pediatric studies demonstrated that the most commonly reported symptoms in children were fever (51.6\%), cough (47.3\%), and sore throat (17.9\%). The most frequently described extra respiratory symptoms were diarrhea (9.7\%) and vomiting (7.2\%). Our results were consistent with those of previous studies (Table 4, Figure 1)..$^{9,21,22}$ The degree of fever in our cases was generally less than $39^{\circ} \mathrm{C}$, as described in previous reports. ${ }^{23,24}$

A significant proportion of the reported children with COVID-19 were asymptomatic.? In contrast, all our patients were symptomatic because they were enrolled at the hospital level where children were only tested if they had symptoms. Some of our patients had unusual presentations, such as isolated gastrointestinal manifestations $(10 \%)$, seizures $(4.8 \%)$, skin rash (1.6\%), and loss of smell (1.6\%), which had been reported in previous studies. ${ }^{15,25,26}$ Non-specific symptoms, such as headache, myalgia, and body aches, were not prominent in this cohort, possibly because of the young age of almost half of the included patients (30 patients were $\leq 5$ years old) who would not be able to verbalize these symptoms properly. 
Table 4 - Summary of the main characteristics of children with COVID-19 included in large systematic reviews and meta-analysis.

\begin{tabular}{|c|c|c|c|c|c|c|c|}
\hline Characteristics & $\begin{array}{c}\text { Present } \\
\text { study }\end{array}$ & $\begin{array}{l}\text { Cui } \\
\text { et } \mathbf{a l}^{22}\end{array}$ & $\begin{array}{l}\text { Liu } \\
\text { et } \mathrm{al}^{21}\end{array}$ & $\begin{array}{l}\text { Ding } \\
\text { et } \mathrm{al}^{20}\end{array}$ & $\begin{array}{l}\text { Mantovani } \\
\text { et } \mathrm{al}^{18}\end{array}$ & $\begin{array}{l}\text { Meena } \\
\text { et a }{ }^{19}\end{array}$ & $\begin{array}{c}\text { Liguoro } \\
\text { et al }{ }^{9}\end{array}$ \\
\hline Number of cases & 62 & 5829 & 4300 & 371 & 2855 & 4857 & 7480 \\
\hline Age (mean, years) & 6 & - & 7.04 & 5.5 & 6.9 & 6.4 & 7.6 \\
\hline Male $(\%)$ & 50 & 55 & 53.6 & 58 & 50.3 & 57 & 52.1 \\
\hline History of contact (\%) & 77.4 & 72 & 81.5 & 86.4 & - & 91 & 85 \\
\hline Fever $(\%)$ & 80.6 & 51 & 52.7 & 51.2 & 47 & 49 & 51.6 \\
\hline Cough (\%) & 48.4 & 41 & 41.9 & 37 & 37 & 45 & 47.3 \\
\hline Diarrhea (\%) & 24.2 & 8 & 4.2 & 7.4 & 4 & 9 & 9.7 \\
\hline Severe/critical cases (\%) & 8.1 & 12 & 0 & 0 & 4 & 4 & 2.7 \\
\hline
\end{tabular}

The laboratory findings in children infected with SARS-CoV-2 showed discrepancies, which could be due to lack of consistency in the reference values among the studies. In the current analysis, different laboratory abnormalities were identified as lymphopenia (22.7\%) and elevated C-reactive protein (40\%), which is consistent with previous reports. ${ }^{27-29}$

Inconsistent with the available data in the literature, the most frequent chest radiography findings among our patients were peripheral ground-glass and consolidative opacities. Although the sensitivity of chest radiography in the diagnosis of COVID-19 is inferior to that of CT scan, exposure to unnecessary radiation in children should be avoided. ${ }^{?}$

The published epidemiological studies demonstrate that children are less likely to develop severe or critical illness when compared to adults. ${ }^{9,13,15,27,29,30}$ Liguoro et $\mathrm{al}^{9}$ confirmed that most children with COVID-19 had mild (42.5\%) to moderate disease $(39.6 \%)$. In addition, children with severe illness represented $2 \%$ and critical illness represented $0.7 \%$ of the reported cases. According to the categories described by Dong et al, ${ }^{15}$ we found that most $(80.6 \%)$ of our symptomatic patients had mild disease, 7 patients (11.3\%) had moderate disease, one patient $(1.6 \%)$ had severe disease, and 4 patients (6.5\%) developed critical illness (and subsequent 3 mortalities from those 4 patients).

Few studies have identified risk factors for developing severe illness in children, such as young age and associated comorbidities. ${ }^{13,15,27,30,31}$ This study included 9 patients $(14.5 \%)$ with pre-existing medical conditions. Among them, one patient had a critical illness and died. A study from Italy reported that 26.2\% of the enrolled children had comorbidities, which is higher than expected within the pediatric population in general, ${ }^{30}$
The current study included 3 deaths (4.8\%). The first patient had multiple risk factors, including congenital heart disease, pulmonary hypertension, and malnutrition. The second mortality occurred in a previously healthy, an African male, who was 11 years old. He had symptoms of fever, vomiting, and diarrhea. He presented with renal impairment that was complicated by multi-organ dysfunction and required PICU admission and mechanical ventilation. In addition, the levels of inflammatory markers were elevated. The previous findings seem to corroborate the multisystem inflammatory syndrome in children, which was described recently among pediatric patients with COVID-19. ${ }^{32,33}$ The third patient was a 4-year-old girl who was not known to have any previous medical illness. She had symptoms of fever, shortness of breath, vomiting, and diarrhea. Chest radiography showed bilateral ground-glass opacities, and the inflammatory markers were elevated. She developed respiratory failure that required mechanical ventilation. The condition was complicated with ARDS, refractory septic shock, and subsequent death.

The reported hospitalization rate among children with SARS-CoV-2 infection was variable. In this study, $33.9 \%$ required hospitalization, including the 4 critical patients who were admitted to the PICU. Interestingly, infants younger than one year were hospitalized more frequently than other age groups $(p=0.02)$. Studies from Italy $(57.7 \%)$ and Spain $(60 \%)$ reported higher hospitalization rates. However, these studies are similar to the present study in terms of cases that were enrolled at the hospital leve. ${ }^{10,30}$

Currently, there are limited published experiences regarding the use of experimental therapies for children with COVID-19. However, symptomatic treatment is used in most cases, and empiric antibiotics are often 
utilized. ${ }^{9,31}$ Consistent with these reports, most (79\%) of our patients received either symptomatic treatment or no treatment, and $16.1 \%$ received antibiotics.

Intravenous immunoglobulin is commonly used in multisystem inflammatory syndrome in children or myocarditis associated with COVID-19. ${ }^{32,33}$ Similarly, in this cohort, it was given to the 2 critical patients and one patient with severe illness.

This study was limited by its retrospective nature, small sample size, single-center, and absence of laboratory or radiological data for some mild cases. Larger multicenter or national studies are essential to determine the epidemiological and clinical features of COVID-19 in children in different countries and to identify predictors of severe illness.

In conclusion, all pediatric age groups are susceptible to COVID-19, with no gender difference. The clinical manifestations of children with COVID-19 are like those of adults but less severe. COVID-19 in children is associated with various laboratory abnormalities and nonspecific chest radiography findings. SARS-CoV-2 infection may result in critical illness and even mortality in subsets of pediatric patients.

Acknowledgment. The authors gratefully acknowledge Editage (www.editage.com) for English language editing.

\section{References}

1. Zhu N, Zhang D, Wang W, Li X, Yang B, Song J, et al. A novel coronavirus from patients with pneumonia in China, 2019. N Engl J Med 2020; 382: 727-733.

2. Alsofayan YM, Althunayyan SM, Khan AA, Hakawi AM, Assiri AM. Clinical characteristics of COVID-19 in Saudi Arabia: A national retrospective study. J Infect Public Health 2020; 13: 920-925.

3. Ministry of Health. MOH Records 290 COVID-19 New Cases, 411 Recoveries on Wednesday. [Updated 2021; Accessed 2020 November 18]. Available fro URL: https://www.moh.gov. sa/en/Ministry/MediaCenter/News/Pages/News-2020-11-18010.aspx

4. Huang C, Wang Y, Li X, Ren L, Zhao J, Hu Y, et al. Clinical features of patients infected with 2019 novel coronavirus in Wuhan, China. Lancet (London, England) 2020; 395: 497-506.

5. Guan WJ, Ni ZY, Hu Y, Liang WH, Ou CQ, He JX et al. Clinical characteristics of coronavirus disease 2019 in China. $N$ Engl J Med 2020; 382: 1708-1720.

6. Wu Z, McGoogan JM. Characteristics of and important lessons from the coronavirus disease 2019 (COVID-19) outbreak in China: summary of a report of 72314 cases from the Chinese Center for Disease Control and Prevention. JAMA 2020; 323: 1239-1242.

7. Center for Disease Control and Prevention. COVID-19 Response Team. Coronavirus Disease 2019 in Children - United States, February 12-April 2, 2020. MMWR Morb Mortal Wkly Rep 2020; 69: 422-426.
8. Dong E, Du H, Gardner L. An interactive web-based dashboard to track COVID-19 in real time. Lancet Infect Dis 2020; 20: 533-534.

9. Liguoro I, Pilotto C, Bonanni M, Ferrari ME, Pusiol A, Nocerino, A et al. SARS-COV-2 infection in children and newborns: a systematic review. Eur J Pediatr 2020; 179: 1029-1046.

10. Tagarro A, Epalza C, Santos M, Sanz-Santaeufemia FJ, Otheo E, Moraleda C, et al. Screening and severity of coronavirus disease 2019 (COVID-19) in children in Madrid, Spain. JAMA Pediatr 2021; 175: 316-317.

11. Zheng Z, Peng F, Xu B, Zhao J, Liu H, Peng J, et al. Risk factors of critical \& mortal COVID-19 cases: A systematic literature review and meta-analysis. J Infect 2020; 81: e16-e25.

12. Jayaraj R, Kumarasamy C, Shetty S, Ram M R, Shaw P. Clinical and conceptual comments on 'Risk factors of critical \& mortal COVID-19 cases: A systematic literature review and metaanalysis'. J Infect 2020; 81: 647-679.

13. Shekerdemian LS, Mahmood NR, Wolfe KK, Riggs BJ, Ross CE, McKiernan CA, et al. Characteristics and outcomes of children with coronavirus disease 2019 (COVID-19) infection admitted to US and Canadian pediatric intensive care units. JAMA Pediatr 2020;. 174: 868-873.

14. Al Harbi S, Ahmed S, Kobeisy N, Mehdawi RS, Salem D, Mosalli RM. COVID-19 patients in Jeddah, Saudi Arabia: clinical, laboratory and radiological aspects. J Biomedical Sci 2020; 9: 7.

15. Dong Y, Mo X, Hu Y, Qi X, Jiang F, Jiang Z, et al. Epidemiology of COVID-19 among children in China. Pediatrics 2020; 145 : e20200702.

16. Goyal P, Choi JJ, Pinheiro LC, Schenck EJ, Chen R, Jabri A, et al. Clinical characteristics of Covid-19 in New York City. $N$ Engl J Med 2020; 382: 2372-2374.

17. Zhou F, Yu T, Du R, Fan G, Liu Y, Liu Z, et al. Clinical course and risk factors for mortality of adult inpatients with COVID-19 in Wuhan, China: a retrospective cohort study. Lancet (London, England) 2020; 395: 1054-1062.

18. Mantovani A, Rinaldi E, Zusi C, Beatrice G, Saccomani MD, Dalbeni A. Coronavirus disease 2019 (COVID-19) in children and/or adolescents: a meta-analysis. Pediatr Res 2020. Online ahead of print.

19. Meena J, Yadav J, Saini L, Yadav A, Kumar J. Clinical features and outcome of SARS-CoV-2 infection in children: a systematic review and meta-analysis. Indian Pediatr. 2020; 57: 820-826.

20. Ding Y, Yan H, Guo W. Clinical characteristics of children with COVID-19: a meta-analysis. Front Pediatr 2020; 8: 431.

21. Liu C, He Y, Liu L, Li F, Shi Y. Children with COVID-19 behaving milder may challenge the public policies: a systematic review and meta-analysis. BMC Pediatr 2020; 20: 410.

22. Cui X, Zhao Z, Zhang T, Guo W, Guo W, Zheng J, et al. A systematic review and meta-analysis of children with coronavirus disease 2019 (COVID-19). J Med Virol 2021; 93: 1057-1069.

23. Cai J, Xu J, Lin D, Yang Z, Xu L, Qu Z et al. A case series of children with 2019 novel coronavirus infection: clinical and epidemiological features. Clin Infect Dis 202012; 71: 1547-1551.

24. Parri N, Lenge M, Buonsenso D. Children with covid-19 in pediatric emergency departments in Italy. N Engl J Med 2020; 383: 187-190. 
25. Schwartz DA. An analysis of 38 pregnant women with COVID-19, Their newborn infants, and maternal-fetal transmission of SARS-CoV-2: maternal coronavirus infections and pregnancy outcomes. Arch Pathol Lab Med 2020. Online ahead of print.

26. Wang JG, Cui HR, Tang HB, Deng XL. Gastrointestinal symptoms and fecal nucleic acid testing of children with 2019 coronavirus disease: a systematic review and meta-analysis. Sci Rep 2020; 10: 17846.

27. Zheng F, Liao C, Fan QH, Chen HB, Zhao XG, Xie ZG, et al. Clinical characteristics of children with coronavirus disease 2019 in Hubei, China. Curr Med Sci 2020; 40: 1-6.

28. Ma H, Hu J, Tian J, Zhou X, Li H, Laws MT, et al. A singlecenter, retrospective study of COVID-19 features in children: a descriptive investigation. BMC Med 2020; 18: 123.

29. Qiu H, Wu J, Hong L, Luo Y, Song Q, Chen D. Clinical and epidemiological features of 36 children with coronavirus disease 2019 (COVID-19) in Zhejiang, China: an observational cohort study. Lancet Infect Dis 2020; 20: 689-696.
30. Parri N, Magistà AM, Marchetti F, Cantoni B, Arrighini A, Romanengo M, et al. Characteristic of COVID-19 infection in pediatric patients: early findings from two Italian pediatric research networks. Eur J Pediatr 2020; 179: 1315-1323.

31. Chao JY, Derespina KR, Herold BC, Goldman DL, Aldrich $\mathrm{M}$, Weingarten J, et al. Clinical characteristics and outcomes of hospitalized and critically ill children and adolescents with coronavirus disease 2019 (COVID-19) at a tertiary care medical center in New York City. J Pediatr 2020; 223: 14-19.

32. Feldstein LR, Rose EB, Horwitz SM, Collins JP, Newhams $\mathrm{MM}$, Son MBF, et al. Multisystem inflammatory syndrome in U.S. children and adolescents. $N$ Engl J Med 2020; 383: 334-346.

33. Dufort EM, Koumans EH, Chow EJ, Rosenthal EM, Muse A, Rowlands J, et al. Multisystem inflammatory syndrome in children in New York State. N Engl J Med 2020; 383: 347-358. 